\title{
Prevalence and correlates of herbal medicine use among Anti-Retroviral Therapy (ART) clients at Queen Elizabeth Central Hospital (QECH), Blantyre Malawi: a cross-sectional study
}

\section{Hawah Mbali ${ }^{1}$, Jessie Jane Khaki Sithole ${ }^{2}$, Alinane Linda Nyondo-Mipando ${ }^{1}$}

1. Department of Health Systems and Policy, School of Public Health and Family Medicine, College of Medicine, University of Malawi/Kamuzu University of Health Sciences

2. Department of Public Health, School of Public Health and Family Medicine, College of Medicine, University of Malawi/Kamuzu University of Health Sciences

Correspondence: Hawah Mbali (hmbali@stud.medcol.mw)

\section{Background}

\section{Abstract}

There has been an unprecedented explosion in the popularity of herbal preparations during the last few decades. Herbal medicines are commonly used by HIV/AIDs clients. There is limited data on the prevalence of herbal medicine and correlating factors of herbal medicine use in Malawi. This study establishes prevalence and factors contributing to the use of herbal medicine among HIV/ AIDS clients attending the ART clinic at QECH, Blantyre Malawi.

Methods

A cross-sectional study design was used to interview 211 conveniently sampled clients at QECH ART clinic. The questionnaire addressed socio-demographic, clinical characteristics, NCD-HIV comorbidity, and herbal medicine utilization. The main outcome of the study was herbal medicine use since the initiation of ART. Logistic regression analysis was done in Stata version 16. Both unadjusted and adjusted models were fitted for potential confounders.

Results

The prevalence of use of herbal medicine was reported in $17.5 \%(n=37)$ of the ART clients. The adjusted logistic regression analysis showed that urban residence was statistically associated with reduced use of herbal medicine (adjusted Odds Ratio -AOR: 0.04, 95\% CI: $0.169,0.976)$.

Conclusion

There is a high prevalence of use of herbal medicine among clients taking ART. Herbal Medicine has the potential to cover the gaps in health coverage in rural communities.

Keywords: Herbal, HIV/AIDS, ART, NCD, comorbidity, prevalence, residence, Malawi.

\section{Introduction}

Complementary and alternative medicines (CAM) are the non-conventional medicine approaches that are practiced mostly outside the health system ${ }^{1}$. Traditional medicine encompasses knowledge, skills, practices founded on beliefs and indigenous life experiences that are used in maintaining health 1. On the other hand, herbal medicine is the use of medicinal plants in the management of diseases, these may be traditional or exogenous plant extracts ${ }^{1,2}$. Many previous studies have focused on CAM (the umbrella) and not traditional herbs separately. Nevertheless, the studies that have been done still show that traditional herbs are generally a common form of $\mathrm{CAM}^{3}$.

There has been an unprecedented explosion in the popularity of herbal preparations in the last few decades. WHO estimated that $80 \%$ of the world's population was using herbal medicine for some aspect of primary health care as of $2008^{4}$. In 2018, the global prevalence for use of herbal medicine went up to $88 \% \%^{5}$. The global prevalence of herbal medicine varies with cultures ${ }^{6}$. Herbal medicine consumption is more related to people's understanding that is influenced by traditional knowledge and lifestyle? For instance: in the Australian culture, wide use of herbs and spices is registered as part of food preservation ${ }^{8}$. Notably, in 2019 WHO reported the highest rate of herbal medicine in Europe and South East Asia at 91\% while in Africa it was at $87 \%$ and even lower in America at $80 \% 0^{5}$. An analysis of the Sub-Saharan Africa region showed that $70 \%$ to $80 \%$ of the general population uses traditional herbal medicine? Herbal medicines are mostly used for treatment of chronic conditions, HIV/AIDS, and HIV-related problems ${ }^{9}$. Regions with longstanding practice of traditional medicine (TM) such as China, Africa, and India, have a considerable number of patients that visit Traditional Healers (TH) before visiting clinics or hospitals providing ART services ${ }^{10}$ and use herbal medicines before starting on ARV s ${ }^{11,12}$. People living with HIV and AIDS (PLWHA) often use African Traditional Herbal Medicines(ATHM) separately or together with conventional medicines including Anti-Retro Virals (ARVs) ${ }^{11}$.

Other than HIV-related conditions, herbal medicines are used for the management of dermatological disorders, nausea, depression, insomnia,weakness ${ }^{13}$, pain, immune supplementation, and stress relief $\mathrm{f}^{1,15}$. There is conflicting literature on the effectiveness of herbal medicine use among HIV and AIDS patients. While an earlier study in South Africa suggested that combined use of herbal medicine and ART has no significant effect on the clinical outcome such as CD4+ Count and viral load among HIV patients ${ }^{11}$, a recent 
qualitative study in Malawi, showed that the use of alternative therapies such as herbal medicine influences defaulting of $\mathrm{ARVs}^{16}$. More information is needed to establish the effects of herbal medicine use on patients' adherence to ART and its long-term complications on clinical outcomes.

The use of herbs among PLWHA differs among different regions. Previous studies have reported varying rates of use of herbal Medicine among HIV patients; $16 \%$ in South Africa ${ }^{12}, 29.3 \%$ in Lebanon ${ }^{17}$, and $60 \%$ in the United States of America ${ }^{18}$. The most used medicinal herbs are aloevera $(49.1 \%)$, ginger $(30.0 \%)$, and garlic $(20.9 \%)^{3}$. In subSaharan Africa and other low resource settings traditional herbal medicine has been the main source of health care in rural communities ${ }^{19}$. Availability and accessibility of herbal medicines contribute to their widespread use in low resource settings?. Furthermore, the herbs are marketed as being useful in managing multiple symptoms and the complete cure of a wide range of conditions ${ }^{12}$. For the past 2 decades, the prevalence of HIV/AIDs has improved from $15 \%$ in 2001 to $9 \%$ in 202020 . There are higher prevalence in females $(10.8 \%)$ compared to males $(7.0 \%) 20$. With the introduction of ARVs, there has been a 30\% decline in all cause mortality rate among those aged 15-59 (2008-2012 thus pre-ART and post-ART periods) ${ }^{21}$. Mortality is specifically high among HIV positive patients: those new on ART $(32.9 \%)$ and ARTnaïve patients $(26.3 \%)^{22}$.In Malawi, earlier herbal concoctions like Mchape in 1995, were introduced and marketed to be for cure of HIV/AIDs ${ }^{23}$. A decade later, Chambe attracted national interest raising hopes to cure HIV/ $\mathrm{AIDs}^{24}$. There have been other herbs like Garani that have shared a similar market trend 25.Recent introduction of herbal medicine like Teras, have come with a different perspective where the focus is on both HIV/AIDs and NCDs like Diabetes, Hypertension and Cancer ${ }^{26}$. There is less emphasis on use of the herbs for cure. Teras is said to have immune boosting benefits and improve clinical outcomes for Immune compromised persons such as those who are HIV/AIDs positive $^{26}$.

The African region has a fair share of strategies and policies for control and regulation of herbal medicine as compared to European regions. It is estimated that $83 \%$ of the countries in Africa have regulatory laws on TCM and only $40 \%$ in Europe 5 . Traditional medicines are promoted in some African countries like South Africa ${ }^{18}$ for the treatment of HIV and its associated symptoms ${ }^{12}$. Nonetheless, implementation of policies and regulations on TCM use in Africa are poor compared to other regions; with only $43 \%$ of member countries having affirmative registration of TCM while $85 \%$ of countries in Europe and American have strict regulations ${ }^{5}$. Although Malawi formulated a TM policy to regulate the practice of herbal Medicine in $2004^{27}$ there remains poor regulation of TM practice at both domestic and international levels ${ }^{28}$. For instance, the Action for Natural Medicine (ANAMED) was adapted from Congo with efforts to train people to grow medicinal plants for the treatment of common ailments as a way of enhancing education and training in traditional medicine. However, as of 2017, the coverage of the project was still minimal ${ }^{29}$. The scarcity of data in the field is clear evidence that industrial research and development in traditional medicine has not been tapped into as per the strategy of the Malawi Ministry of Health ${ }^{27}$.

Given the disparities and lack of data on the use of herbal medicine among PLWHA in Malawi, this study assessed the prevalence and correlates of herbal medicine use among clients attending the ART Clinic at QECH in Southern Malawi. This information will inform policy makers, researchers, and health professionals on herbal use among clients on ART and its impact on health practices.

\section{Methods}

\section{Study Design}

We conducted a clinic-based cross-sectional study where interviewer guided questionnaires were administered to 211 participants from 3rd November to 21st November 2018. The questionnaire contained sections that assessed sociodemographic, clinical characteristics, and herbal medicine utilization.

\section{Setting of the study}

The study was conducted at Queen Elizabeth Central Hospital, a tertiary hospital in the southern part of Malawi. The hospital is a referral and teaching hospital that serves the southern region of Malawi. It also manages referred cases from other central and district hospitals depending on their need for equipment or expertise. By August 2017, the ART clinic at this hospital had a cumulative register of over 28,000 clients. According to the hospital's ART register book; 11,933 clients were in active attendance at the time of the study. The ART Clinic is open from Monday to Saturday. The staff at the clinics consists of Medical Officers, Clinical Officers, State Registered Nurses, Nurse Midwife Technicians, Pharmacy and Lab Technicians as well as HIV counselors and data clerks. The clinic attends to 150 to 200 clients per day consisting of both pediatric and adult HIV patients. Referrals to the mainstream hospital are made where necessary.

\section{Sample size calculation}

Cochran's sample size calculation formula (sample size calculation formula for one proportion) was used in the study. As of June 2017, the ART clinic had a sum of 11,933 people registered as patients under its ART clinic. There was no data on the existing prevalence of herbal medicine use in Malawi, hence a prevalence of $16 \%$ found in a study done by Hughes et al. in South Africa, published in 2012 was used 12. Using a margin of error of 0.05 and a confidence interval of $95 \%$, a sample size of 203 was realized. The sample size was adjusted for loss of data due to various factors such as transcription error by $5 \%$ to yield a maximum sample size of 234 .

\section{Recruitment of Study Participants}

We conveniently approached clients in the queue while they were waiting for services at the ART facility. Strategies to keep the flow without delays were employed; for example, allowing participants to get back on the spot they were taken from at the end of the interview. A checklist (appendix IV) was used to identify eligible participants for the study and we included those that were HIV-infected, aged 18 years or older, consented to the study, and on ART for a minimum period of 3 months. We selected a minimum of 3 months on treatment because a patient would have stabilized on therapy and could provide well-solicited information at that point. This period has also been used in a previous cross sectional study which was a 10 year evaluation of the antiretroviral therapy roll out in South Africa ${ }^{30}$. 


\section{Data collection}

The questionnaire contained sections that assessed sociodemographic, clinical characteristics, and herbal medicine utilization. The questionnaire was first prepared in English and Chichewa and back-translated to English to ensure that it retains its intended meaning. The questionnaire was pretested to identify potential problems, anticipated interpretations, and cultural objections to any of the questions on 5 respondents at the same facility of the study. The questionnaire was adapted from other similar studies on the use of traditional herbal medicines in HIV/AIDS patients ${ }^{18,17,12,3}$ with a little modification to suit the Malawian context. Questionnaire guided interviews were administered by a study team of 4 research assistants including the Principle Investigator. The questionnaire was administered one on one in a consultation room away from the clinic staff and the rest of the clients at the facility to ensure privacy. Clinical data, for example, adherence was collected from patients' health passport books or files derived from patients' pill count. In this study, herbal medicine was considered as any plant extract used in the treatment and or prevention of disease $\mathrm{e}^{1}$.

\section{Outcome variable}

Our main statistical outcome for the study was to estimate the prevalence of people that were using herbal medicine whilst on ART. Furthermore, we aimed at investigating the factors associated with the current use of herbal medicine. Consequently, the study had a binary outcome which was defined as a one (1) for those who were using herbal medicine at the time of the study and zero (0) for those that were not using any.

\section{Independent variables}

The selection of independent covariates was based on previous literature from other countries on the use of herbal medicine amongst ART patients ${ }^{31,32,30}$. The covariates that were adopted for this study were: sex of the participant, age, religion, marital status, area of residence (urban or rural), monthly income, adherence to ART, duration on ART, ever switched an ART regimen, and NCD-HIV comorbidity.

\section{Statistical analysis}

A frequency table was used to describe the characteristics of the sample that was collected. A chi-square test was used to investigate the association between categorical variables and the use of herbal medicine. Due to the nature of our outcome of interest, a logistic regression model was used for our multivariate analysis. All analyses were conducted in Stata version 16 at a $5 \%$ significance level.

\section{Results}

\section{Characteristics of Participants}

A total of 211 participants were included in the study. All participants were of a black racial group. The prevalence of current use of herbal medicine was $17.5 \%(\mathrm{n}=37)$ whilst that of previous use was $36.0 \%(n=76)$. A total of $98(46.5 \%)$ of the study participants were neither using herbal medicine at the time of the study nor had they ever used herbal medicine in their lives.

The sample comprised more women (63.5\%) than men. Similarly, a larger proportion $(73 \%)$ of herbal medicine users were women. The descriptive analysis further showed that about $78.7 \%$ of the study participants were residing in the urban area at the time of the study. However, only $27.5 \%$
Table 1: Characteristics of the sample

\begin{tabular}{|c|c|c|c|c|c|}
\hline \multirow[t]{2}{*}{ Variable } & Never used & $\begin{array}{l}\text { Used in } \\
\text { the past }\end{array}$ & $\begin{array}{l}\text { Use at } \\
\text { time of } \\
\text { study }\end{array}$ & Total & $\begin{array}{c}\text { Chi-square } \\
\text { P-value }\end{array}$ \\
\hline & $\mathrm{n}(\%)$ & $\mathrm{n}(\%)$ & $\mathrm{n}(\%)$ & $\mathrm{n}(\%)$ & \\
\hline Sex & & & & & 0.029 \\
\hline Male & $45(45.92)$ & $\begin{array}{c}22 \\
(28.95)\end{array}$ & $\begin{array}{c}10 \\
(27.03)\end{array}$ & $\begin{array}{c}77 \\
(36.49)\end{array}$ & \\
\hline Female & $53(54.08)$ & $\begin{array}{c}54 \\
(71.05)\end{array}$ & $\begin{array}{c}27 \\
(72.97)\end{array}$ & $\begin{array}{c}134 \\
(63.51)\end{array}$ & \\
\hline Age & & & & & 0.157 \\
\hline$\leq 30$ years & $13(13.27)$ & $\begin{array}{c}20 \\
(26.32)\end{array}$ & $6(16.22)$ & $\begin{array}{c}39 \\
(18.48)\end{array}$ & \\
\hline $31-40$ years & $46(46.94)$ & $\begin{array}{c}26 \\
(34.21)\end{array}$ & $\begin{array}{c}13 \\
(35.14)\end{array}$ & $\begin{array}{c}65 \\
(40.28)\end{array}$ & \\
\hline $41+$ years & $39(39.80)$ & $\begin{array}{c}30 \\
(39.47)\end{array}$ & $\begin{array}{c}18 \\
(48.65)\end{array}$ & $\begin{array}{c}87 \\
(41 / 23)\end{array}$ & \\
\hline Marital Status & & & & & 0.101 \\
\hline Single & $8(8.16)$ & $\begin{array}{c}16 \\
(21.05)\end{array}$ & $3(8.11)$ & $\begin{array}{c}27 \\
(12.80)\end{array}$ & \\
\hline $\begin{array}{l}\text { Married/ } \\
\text { cohabiting/ } \\
\text { living together }\end{array}$ & 63 (64.29) & $\begin{array}{c}40 \\
(52.63)\end{array}$ & $\begin{array}{c}25 \\
(57.57)\end{array}$ & $\begin{array}{c}128 \\
(60.66)\end{array}$ & \\
\hline $\begin{array}{l}\text { Wid o w e d / } \\
\text { d i v o r c e d / } \\
\text { separated }\end{array}$ & $27(27.53)$ & $\begin{array}{c}20 \\
(26.32)\end{array}$ & $9(24.32)$ & $\begin{array}{c}56 \\
(26.54)\end{array}$ & \\
\hline $\begin{array}{l}\text { Educational } \\
\text { attainment }\end{array}$ & & & & & 0.324 \\
\hline $\begin{array}{l}\text { None/primary } \\
\text { education }\end{array}$ & $43(43.88)$ & $\begin{array}{c}28 \\
(36.84)\end{array}$ & $\begin{array}{c}19 \\
(51.35)\end{array}$ & $\begin{array}{c}90 \\
(42.65)\end{array}$ & \\
\hline $\begin{array}{l}\text { Second ary } \\
\text { and higher }\end{array}$ & $55(56.12)$ & $\begin{array}{c}48 \\
(65.14)\end{array}$ & $\begin{array}{c}18 \\
(48.65)\end{array}$ & $\begin{array}{c}121 \\
(57.33)\end{array}$ & \\
\hline $\begin{array}{l}\text { Mo n t h I y } \\
\text { income }\end{array}$ & & & & & $0.008^{\S}$ \\
\hline $\begin{array}{l}\text { Less than } \\
\text { MK50,000 }\end{array}$ & $52(53.06)$ & $\begin{array}{c}44 \\
(57.81)\end{array}$ & $\begin{array}{c}26 \\
(70.27)\end{array}$ & $\begin{array}{c}122 \\
(57.82)\end{array}$ & \\
\hline $\begin{array}{l}\text { At least } \\
\text { MK50,000 }\end{array}$ & $17(17.35)$ & $2(2.63)$ & $2(5.41)$ & $\begin{array}{c}21 \\
(9.95)\end{array}$ & \\
\hline No response & 29 (29.59) & $\begin{array}{c}36 \\
(39.47)\end{array}$ & $9(24.52)$ & $\begin{array}{c}68 \\
(32.23)\end{array}$ & \\
\hline $\begin{array}{l}\text { Area } \\
\text { residence }\end{array}$ & & & & & 0.025 \\
\hline $\begin{array}{l}\text { Peri urban or } \\
\text { rural }\end{array}$ & $14(14.29)$ & $\begin{array}{c}18 \\
(23.68)\end{array}$ & $\begin{array}{c}13 \\
(35.14)\end{array}$ & $\begin{array}{c}45 \\
(21.33)\end{array}$ & \\
\hline Urban & $84(85.71)$ & $\begin{array}{c}58 \\
(76.32)\end{array}$ & $\begin{array}{c}24 \\
(64.86)\end{array}$ & $\begin{array}{c}166 \\
(78.67)\end{array}$ & \\
\hline $\begin{array}{l}\text { Comorbidity } \\
\text { with an NCD }\end{array}$ & & & & & 0.072 \\
\hline Yes & $11(11.22)$ & $\begin{array}{c}11 \\
(14.47)\end{array}$ & $\begin{array}{c}10 \\
(27.03)\end{array}$ & $\begin{array}{c}10 \\
(27.03)\end{array}$ & \\
\hline No & 87 (88.78) & $\begin{array}{c}65 \\
(85.53) \\
\end{array}$ & $\begin{array}{c}27 \\
(72.97) \\
\end{array}$ & $\begin{array}{c}27 \\
(72.97)\end{array}$ & \\
\hline $\begin{array}{lcc}\text { A } & R & T \\
\text { adherence } & \end{array}$ & & & & & 0.483 \\
\hline No & $48(48.98)$ & $\begin{array}{c}31 \\
(40.79)\end{array}$ & $\begin{array}{c}15 \\
(40.54)\end{array}$ & $\begin{array}{c}94 \\
(44.55)\end{array}$ & \\
\hline Yes & $50(51.02)$ & $\begin{array}{c}45 \\
(59.21) \\
\end{array}$ & $\begin{array}{c}22 \\
(59.46) \\
\end{array}$ & $\begin{array}{c}117 \\
(55.45)\end{array}$ & \\
\hline $\begin{array}{l}\text { Duration on } \\
\text { ART }\end{array}$ & & & & & $0.040^{\S}$ \\
\hline $\begin{array}{l}\text { Less than } 1 \\
\text { year }\end{array}$ & $22(22.45)$ & $7(9.21)$ & $2(5.41)$ & $\begin{array}{c}31 \\
(14.69)\end{array}$ & \\
\hline $1-5$ years & $28(28.57)$ & $\begin{array}{c}22 \\
(28.95)\end{array}$ & $9(24.32)$ & $\begin{array}{c}59 \\
(27.96)\end{array}$ & \\
\hline $6-9$ years & $21(21.43)$ & $\begin{array}{c}27 \\
(35.53)\end{array}$ & $\begin{array}{c}10 \\
(27.03)\end{array}$ & $\begin{array}{c}58 \\
(27.49)\end{array}$ & \\
\hline $10+$ years & $27(27.55)$ & $\begin{array}{c}20 \\
(26.52)\end{array}$ & $\begin{array}{c}16 \\
(43.24)\end{array}$ & $\begin{array}{c}63 \\
(29.86)\end{array}$ & \\
\hline
\end{tabular}

$\S=$ Fisher's exact test

of the study participants had a monthly income of at least MK50, 000 (US\$64). Further descriptive results are presented in Appendix ix, table 1.

Data on adherence was collected from the health passport book and ART follow-up charts in form of percentage pills used from the previous refill. We used the adherence markup of $95 \%$ to categorize adherence into optimal $(=>95 \%)$ and suboptimal adherence $(<95 \%)$. This was adapted from the Visual Analog scale ${ }^{33}$, a system of classifying medication adherence that has been validated in low resource settings $\mathrm{s}^{33,34}$. 
Table 2: Risk factors for previous and current use of herbal medicine

\begin{tabular}{|c|c|c|c|c|}
\hline \multirow{3}{*}{ Variable } & \multirow{2}{*}{\multicolumn{2}{|c|}{$\begin{array}{l}\text { Never used vs } \\
\text { Used in the past }\end{array}$}} & \multirow{2}{*}{\multicolumn{2}{|c|}{ Never used vs Use at time of study }} \\
\hline & & & & \\
\hline & RRR & $95 \% \mathrm{Cl}$ & RRR & $95 \% \mathrm{Cl}$ \\
\hline \multicolumn{5}{|l|}{ Sex } \\
\hline Male & 1 (Ref) & & 1 (Ref) & \\
\hline Female & 2.326 & $(1.099-4.920)^{*}$ & 3.314 & $(1.243-8.838)^{\star}$ \\
\hline \multicolumn{5}{|l|}{ Age } \\
\hline$\leq 30$ years & 1 (Ref) & & 1 (Ref) & \\
\hline $31-40$ years & 0.580 & $(0.192-1.753)$ & 0.550 & $(0.130-2.320)$ \\
\hline $41+$ years & 0.924 & $(0.313-2.729)$ & 1.275 & $(0.314-5.1671)$ \\
\hline \multicolumn{5}{|l|}{ Marital Status } \\
\hline Single & 1 (Ref) & & 1 (Ref) & \\
\hline $\begin{array}{l}\text { Married/cohabiting/ } \\
\text { living together }\end{array}$ & 0.421 & $(0.126-1.408)$ & 1.227 & $(0.226-6.664)$ \\
\hline $\begin{array}{l}\text { Widowed/divorced/ } \\
\text { separated }\end{array}$ & 0.370 & $(0.096-1.431)$ & 0.703 & $(0.106-4.674)$ \\
\hline \multicolumn{5}{|l|}{ Monthly income } \\
\hline Less than MK50,000 & 1 (Ref) & & 1 (Ref) & \\
\hline At least MK50,000 & 0.140 & $(0.028-0.704)^{*}$ & 0.149 & $(0.026-0.842)^{*}$ \\
\hline No response & 1.065 & $(0.513-2.208)$ & 0.432 & $(0.156-1.198)$ \\
\hline \multicolumn{5}{|l|}{ Area of residence } \\
\hline Peri-urban or rural & 1 (Ref) & & 1 (Ref) & \\
\hline Urban & 0.654 & $(0.279-1.529)$ & 0.438 & $(0.164-1.165)$ \\
\hline \multicolumn{5}{|l|}{$\begin{array}{l}\text { Comorbidity with an } \\
\text { NCD }\end{array}$} \\
\hline Yes & 1 (Ref) & & 1 (Ref) & \\
\hline no & 0.528 & $(0.192-1.454)$ & 0.265 & $(0.089-0.791)^{*}$ \\
\hline \multicolumn{5}{|l|}{ Duration on ART } \\
\hline Less than 1 year & 1 (Ref) & & 1 (Ref) & \\
\hline $1-5$ years & 2.126 & $(0.721-6.269)$ & 3.170 & $(0.575-7.460)$ \\
\hline $6-9$ years & 3.738 & $(1.256-11.125)^{\star}$ & 4.077 & $(0.736-10.603)$ \\
\hline $10+$ years & 2.229 & $(0.733-6.775)$ & 6.026 & $(3.147-11.650)^{*}$ \\
\hline
\end{tabular}

\section{Discussion}

In this study, the prevalence of herbal medicine use was $17.5 \%$. Herbal use was the highest among females $(73.0 \%$ ) those with less than K50,000 (US\$ 64.00) monthly earnings (70\%), those residing in urban areas $(64.9 \%)$, and those that had been on ART for more than 10 years $(43.2 \%)$.

The prevalence found in this study is similar to an earlier study done in South Africa in 2012 where prevalence was found to be $16 \%{ }^{12}$. Recent studies have looked at traditional medicine from an angle of $\mathrm{CAM}^{35,32,30,3}$. In these studies, herbal medicine emerged the most common method. However, when compared to recent studies in the region, our current has a relatively higher prevalence of concurrent use of herbal medicine and ART. For example, a descriptive study in South Africa carried out in 2016 found a low concurrent ARV and ATM use $(5.0 \%)^{11}$ and another study found the prevalence of use of herbal medicine and ART to be $8.1 \%{ }^{30}$. Unlike our study, these two studies were both done in a multiracial community and it is reported that black people had a high prevalence $(8.2 \%)$ of concurrent use unlike Indians, colored (equally $5 \%$ and whites $0 \%)^{30}$. It is quite evident that the use of herbal medicine remains an important component of the African culture which is predominantly black ${ }^{36}$ with African countries like Uganda that had all black participants having higher prevalence $(32.2 \%) 37$. Such patterns in herbal medicine use demonstrate the importance of traditional herbal medicine in Malawi and the need for consideration of this when making public health policies.

Other aspects of culture like religion have been shown to increase the likelihood of herbal medicine use. In this study, being Muslim has shown to increase

This system has been used in other related studies to classify ART adherence ${ }^{34,35}$.

\section{Factors associated with herbal medicine use}

Appendix ix,table 2 presents the results of the logistic regression analysis. We fitted both a univariate (unadjusted) model and a model adjusted for potential confounders. The adjusted model used all the variables reported in the univariate model. Living in an urban was found to be significantly associated with reduced herbal medicine use at a $5 \%$ significance level in the adjusted model. Use of herbal medicine was reduced by 59\% (Coefficient: $0.41,95 \%$ CI: $0.16,0.976$ ) among participants living in the urban areas compared to those living in rural areas.

Although the other variables were not statistically significant, some interesting trends were still observed. For instance, herbal medicine use was two times [AOR: 2396, 95\% CI: $0.908,6.321]$ higher among females than males. Furthermore, using herbal medicine increased by 3 times [AOR: 3.28, 95\% CI: 0.889, 12.08] among Muslim participants than Christian participants. Interestingly, the use of herbal medicine were reduced by 58\% (AOR: $0.42,95 \%$ CI: $0.178,1.0$ ) among participants that had never had their ART regimen switched. In addition to this, the use of herbal medicine was reduced by about $60 \%$ (AOR: 0.40 95\% CI: 0.16, 1.01) among participants that did not have any NCD-HIV comorbidities. the use of herbal medicine. This is consistent with a systemic review done in Sub-Saharan Africa in $2018^{31}$. Religious institutions are the largest source of CAM, about $41 \%$ in a study in Ethiopia ${ }^{38}$. Education and awareness on herbal medicine should be done through religious institutions as an effective way of distributing relevant information on herbal medicine. Like most studies, being female was found to be a contributing factor to herbal medicine use ${ }^{31,30,12}$. The general picture of HIV/AIDS in Malawi and Africa at large is such that HIV positive individuals are mostly female $(12.8 \%$ in the 15-64 age group $)^{39,40}$. This could explain the high female participation in the current study and studies with similar findings ${ }^{31,30,12}$.

The current study found the prevalence of herbal medicine use to be lower among those residing in urban areas. This is consistent with findings of a study that found that a substantial magnitude of herbal medicine use in rural communities ${ }^{41}$ where the majority of the type of herbs used were traditionally cultivated herbs that are taken raw or boiled in water to make some form of tea ${ }^{41}$. Herbal medicine is cheap and easily accessible to most people especially people living in rural areas ${ }^{42}$. Despite its efforts in universal health coverage, Malawi still faces uneven distribution of health facilities in rural communities, which has led to geographical inequities in population coverage and financial protection ${ }^{43}$. Affordability of medical costs at private facilities and transport costs remains the main barrier to universal health 
coverage ${ }^{43}$. Formal recognition and integration of traditional medicine into conventional medicine may increase health care coverage and is a potential source of income for providers hence reduction of poverty.

Studies that were done on the prevalence of herbal medicine use among patients with only NCD show a high rate of up to $61 \%{ }^{44}$. This study showed that not having NCD-HIV comorbidity reduces the odds of using herbal medicine alongside ARVs. Research has illustrated the web of causation that exists in people with HIV-NCD comorbidity ${ }^{45}$. The common relationship illustrated is the inflammatory effects of HIV, ARV toxicity ${ }^{45}$. Some studies have shown that herbal medicines are used to treat HIVassociated symptoms and ARV side effects ${ }^{13,30,36,11}$. In some areas, herbal medicines have been used to treat $\mathrm{NCDs}^{44}$. It is therefore not surprising that NCD-HIV comorbidity is associated with an increased prevalence of concomitant herbal medicine and ARV use. Policies and training related to herbal medicine should encompass people with NCD-HIV comorbidity. There is a need to look into the effects of the different herbal remedies in such a group of people given the interactions at stake.

The current study shows no significant association between concomitant ART-herbal medicine use and ART adherence. Nonetheless, those that have never had ART switch had reduced odds of ART-herbal medicine concomitant use. Most studies have found that herbal medicine use is associated with reduced ARV adherence ${ }^{34}$ which has been attributed to drug resistance hence the switch ${ }^{46}$. On the other hand, patients that have been switched to a new regimen may experience new symptoms as side effects of the new regimen that motivate their use of herbal medicine47. Patients need to be informed on the possible effects of new regimens as well as on the importance of ART adherence and the dangers of ART non-adherence.

\section{Study strengths and limitations}

This is the first study to determine the prevalence of herbal medicine use in Malawi and its impact on health. The study is multifaceted and captures multiple outcomes about herbal medicine use. Conducting this study at a health facility may have negatively affected participants' willingness to give information. The outcomes in this study were largely dependent on participants' memory such that findings may be affected by recall bias. This may have yielded an incomplete understanding of the magnitude of herbal medicine use among PLWHA. To reduce these limitations, the study was conducted by a team of research assistants that were not health care providers at the facility. Participants were given ample time to remember all the necessary information and participants were encouraged to give queries or additional information on the study matter. The convenient selection of study participants makes it difficult to generalize the study findings to the whole population.

Missing clinical information for example data on adherence to ART may have affected our view of the impact of herbal use on HIV/AIDS patients. We recommend clinical research be done to look into the clinical impact of concurrent herbal use with a focus on more objective outcomes like Viral Load, CD4 count.

\section{Conclusions}

The prevalence of herbal medicine use among HIV patients accessing care at QECH ART clinic is higher than that of other countries in the region. Predictors of herbal medicines use include rural residency, female gender, being Muslim, having one's ARVs switched to a new regimen and having NCD-HIV comorbidity. Given the high prevalence of herbal medicine use, consideration needs to be made on the role of herbal medicine in health policy formulation. Clinical trials should be conducted to assess the effect of concurrent use of herbal medicine and ART on patient outcomes. Religion has an important bearing on herbal medicine use and maybe an important entry point for discussions on matters of herbal medicine use. Herbal medicine has the potential to meet health coverage needs in rural communities upon thorough evaluation.

\section{Availability of data and material}

The Stata do file and data set used for this study can be downloaded from https://github.com/jessiekhaki/herbalmedicine-use-among-ART-clients-in-BT.git

\section{Funding}

This research was supported by funding from the office of the Postgraduate Dean, College of Medicine. Dr. NyondoMipando is supported by Malawi HIV Implementation Research Scientist Training program (Fogarty: D43 TW010060). The funders had no role in the design of the study and collection, analysis and interpretation of data and in writing the manuscript.

\section{Authors' Contributions}

The study was conceptualized, developed and conducted by HM under the supervision of ALNM. JK provided statistical support for the study. HM drafted the initial manuscript and the manuscript was further reviewed and edited by JK and ALNM. All authors read and approved the final manuscript.

\section{Ethics approval and consent to participate}

This study received ethical approval from the College of Medicine Research Ethics Committee on 20th April 2018 (P10/17/2307). All participants gave their consent to participate in the study. Participant identity was kept anonymous and their opinions were not shared by anyone outside the study team.

\section{Acknowledgements}

Sincere gratitude to field workers Adamson Siula, Mateyo Kafulafula, and Victoria Mukhula for their assistance in the collection of the data. Appreciation extended to the clients and staff at the ART clinic for granting permission to conduct this study at the facility. Most importantly, would like to thank study participants for their consent and cooperation in taking part in the study. This research topic was inspired by the African Center for Excellence of Public Health and Herbal Medicine (ACEPHEM) -College of Medicine.

\section{References}

1. World Health Organization [WHO]. Traditional, complementary and integrative medicine. World Heal Organ. 2019:https://www.who.int/traditionalcomplementary-inte.

2. Firenzuoli F, Gori L. Herbal Medicine Today : Clinical and Research Issues. 2007;4:37-40. doi:10.1093/ecam/nem096

3. Bahall M. Prevalence, patterns, and perceived value of complementary and alternative medicine among HIV patients: A descriptive study. BMC Complement Altern Med. 2017;17(1):1-9. doi:10.1186/s12906-017-1928-4

4. Jon C Tilburt a TJK b. Herbal Medicine Research and Global Health: An Ethical Analysis.; 2008.

5. Who Global Report on Traditional and Complementary Medicine 2019.; 2019. 
6. Harris PE, Cooper KL, Relton C, Thomas KJ. Prevalence of complementary and alternative medicine (CAM) use by the general population: A systematic review and update. Int J Clin Pract. 2012;66(10):924-939. doi:10.1111/j.17421241.2012.02945.x

7. Akhagba OM. Cultural influence in the consumption of herbal medicine among Nigerian women: a theoretical exploration. Misc Anthropol Sociol. 2017;18(May):193-206.

8. Tapsell LC, Hemphill I, Cobiac L, et al. Health benefits of herbs and spices: the past, the present, the future. Med J Aust. 2006;185(4 Suppl). doi:10.5694/j.1326-5377.2006.tb00548.x

\section{Traditional WHO, Strategy M. WHO Traditional Medicine Strategy.}

10. General Guidelines for Methodologies on Research and Evaluation of Traditional Medicine World Health Organization. 2000.

11. Sibanda M, Manimbulu NM, Naidoo P. Concurrent use of antiretroviral and african traditional medicines amongst people living with HIV/AIDS (PLWA) in the eThekwini Metropolitan area of KwaZulu Natal. Afr Health Sci. 2016;16(4):1118-1130. doi:10.4314/ahs.v16i4.30

12. Tradit AJ, Altern C, Hughes GD, et al. PREVALENCE AND PREDICTORS OF TRADITIONAL MEDICINE UTILIZATION AMONG PERSONS LIVING WITH AIDS ( PLWA ) ON ANTIRETROVIRAL (ARV) AND PROPHYLAXIS TREATMENT IN BOTH RURAL AND URBAN AREAS IN SOUTH AFRICA Clarks \& Associates Statistical Consulting, Nashville . 2012;9.

13. Jünemann R, Schmidt T. Materialflußsysteme. Systemtechnische Grundlagen: 1. Aufl. udT: Materialfluß und Logistik. 1999;1(8):1002-1018. doi:10.1080/09540120701767216.Complementary

14. Peltzer K, Preez NF Du, Ramlagan S, Fomundam H. Use of traditional complementary and alternative medicine for HIV patients in KwaZuluNatal, South Africa. BMC Public Health. 2008;8(November 2003):1-14 doi:10.1186/1471-2458-8-255

15. Syed IA, Sulaiman SAS, Hassali MA, Thiruchelvam K, Syed SH, Lee CKC. Beliefs and practices of complementary and alternative medicine (CAM) among HIV/AIDS patients: A qualitative exploration. Eur J Integr Med. 2016;8(1):4147. doi:10.1016/j.eujim.2015.09.135

16. Chirambo L, Valeta M, Mary T, Kamanga B, Nyondo-mipando AL. Factors influencing adherence to antiretroviral treatment among adults accessing care from private health facilities in Malawi. 2019:1-11.

17. Abou-Rizk J, Alameddine M, Naja F. Prevalence and Characteristics of CAM Use among People Living with HIV and AIDS in Lebanon: Implications for Patient Care. Evidence-based Complement Altern Med. 2016;2016. doi:10.1155/2016/5013132

18. Fairfield KM, Eisenberg DM, Davis RB, Libman H, Phillips RS. Patterns of use, expenditures, and perceived efficacy of complementary and alternative therapies in HIV-infected patients. Arch Intern Med. 1998;158(20):2257-2264. doi:10.1001/archinte.158.20.2257

19. Id JH, Seguin R, Phanga T, et al. Facilitators and barriers to traditional medicine use among cancer patients in Malawi. 2019:1-14.

20. Nutor JJ, Duah HO, Agbadi P, Duodu PA, Gondwe KW. Spatial analysis of factors associated with HIV infection in Malawi: Indicators for effective prevention. BMC Public Health. 2020;20(1):1-14. doi:10.1186/s12889-020 09278-0

21. Payne CF, Kohler HP. The population-level impact of public-sector antiretroviral therapy rollout on adult mortality in rural Malawi. Demogr Res. 2017;36(1):1081-1108. doi:10.4054/DemRes.2017.36.37

22. Matoga MM, Rosenberg NE, Stanley CC, et al. Inpatient mortality rates during an era of increased access to HIV testing and ART: A prospective observational study in Lilongwe, Malawi. PLoS One. 2018;13(2):1-12. doi:10.1371/journal. pone. 0191944

23. Probst . Mchape '95, or, the sudden fame of Billy Goodson Chisupe: Healing, social memory and the enigma of the public sphere in post-Banda malawi. Africa. 69(1), doi. 2011;69(1):108-138.

24. Simwaka A, Peltzer K, Maluwa-Banda D. Indigenous Healing Practices in Malawi. J Psychol Africa. 2007;17(1-2):155-161. doi:10.1080/14330237.2007. 10820162

25. nyasatimes. HIV 'cure' Garani MW1 on high demand in Malaw. Online news. http://www.nyasatimes.com/hiv-cure-garani-mw1-on-high-demand-inmalawi. Published 2015.

26. Teras. Teras AIDS, cancer, diabetes cure. http://www.teras.com/teras-juice Published 2017. Accessed February 18, 2021.
27. Ministry of Health G of M. Traditional Medicine Policy for Malawi. 2004:618.

28. Gerald S. MekeReginald F.E. MumbaRichard J. BwanaliVivienne L. WilliamsVivienne L. Williams. The trade and marketing of traditional medicines in southern and central Malawi. Int J Sustain Dev World Ecol. 2017;1(24):73-87.

29. Project TM. MEDICINAL PLANTS SOURCE OF HOPE. https://www. malawiproject.org/medicinal-plants-source-of-hope/. Published 2019. Accessed October 7, 2020

30. Nlooto M, Naidoo P. Traditional, complementary and alternative medicine use by HIV patients a decade after public sector antiretroviral therapy roll out in South Africa: A cross sectional study. BMC Complement Altern Med. 2016;16(1):1-12. doi:10.1186/s12906-016-1101-5

31. James PB, Wardle J, Steel A, Adams J. Traditional, complementary and alternative medicine use in Sub-Saharan Africa: A systematic review. BMJ Glob Heal. 2018;3(5). doi:10.1136/bmjgh-2018-000895

32. Aziato L, Antwi HO. Facilitators and barriers of herbal medicine use in Accra, Ghana: An inductive exploratory study. BMC Complement Altern Med. 2016. doi:10.1186/s12906-016-1124-y

33. Erb S, Letang E, Glass T, et al. A Simple Visual Analog Scale is a Valuable Tool to Assess Self-Reported Adherence in HIV-Infected Patients on Antiretroviral Treatment in a Resource-Limited Setting. J AIDS Clin Res. 2017;08(09). doi:10.4172/2155-6113.1000731

34. Peltzer K, Friend-du Preez N, Ramlagan S, Fomundam H, Anderson J, Chanetsa L. Antiretrovirals and the use of traditional, complementary and alternative medicine by HIV patients in Kwazulu-Natal, South Africa: A longitudinal study. African J Tradit Complement Altern Med. 2011;8(4):337345. doi:10.4314/ajtcam.v8i4.1

35. Kelso-Chichetto NE, Okafor CN, Harman JS, Canidate SS, Cook CL, Cook RL. Complementary and Alternative Medicine Use for HIV Management in the State of Florida: Medical Monitoring Project. J Altern Complement Med. 2016;22(11):880-886. doi:10.1089/acm.2016.0190

36. Sibanda M, Naidoo P, Nlooto M. International Journal of Public Health and Safety African Traditional Medicine Use amongst People Living with HIV / AIDS in Sub-Saharan Africa in the Era of Antiretroviral Therapy. Int J Public Heal Saf. 2016;1(2):2-5.

37. Langlois-Klassen D, Kipp W, Jhangri GS RT. Use of traditional herbal medicine by AIDS patients in Kabarole District, western Uganda. Am J Trop Med Hyg. 2007;8(77):757-763.

38. Endale Gurmu A, Teni FS, Tadesse WT. Pattern of Traditional Medicine Utilization among HIV/AIDS Patients on Antiretroviral Therapy at a University Hospital in Northwestern Ethiopia: A Cross-Sectional Study. Evidence-based Complement Altern Med. 2017;2017. doi:10.1155/2017/1724581

39. UNAIDS. UNAIDS Data 2018. 2018:1-376.

40. Ministry of Health M. Malawi population-based impact assessment. 2016;(December 2016):1-4.

41. Schmitt \& Segert. $\square \square \square \square \square$ NIH Public Access. Bone. 2008;23(1):1-7. doi:10.1177/0733464811424152.Traditional

42. Ruano P, Delgado LL, Picco S, et al. We are IntechOpen, the world's leading publisher of Open Access books Built by scientists, for scientists TOP $1 \%$. Intech. 2016;(tourism):13.

43. Abiiro GA, Mbera GB, De Allegri M. Gaps in universal health coverage in Malawi: A qualitative study in rural communities. BMC Health Serv Res. 2014;14(1):1-10. doi:10.1186/1472-6963-14-234

44. Hughes GD, Aboyade OM, Beauclair R, Mbamalu ON, Puoane TR. Characterizing Herbal Medicine Use for Noncommunicable Diseases in Urban South Africa. 2015;2015.

45. Petersen M, Yiannoutsos CT, Justice A, Egger M. Observational research on NCDs in HIV-positive populations: Conceptual and methodological considerations. J Acquir Immune Defic Syndr. 2014;67(SUPPL.1):1-18. doi:10.1097/QAI.0000000000000253

46. Redd AD, Mukonda E, Hu N-C, et al. ART Adherence, Resistance, and Long-term HIV Viral Suppression in Postpartum Women. Open Forum Infect Dis. 2020;7(10):1-4. doi:10.1093/ofid/ofaa346

47. Gelaw YK, Adugna B, Tsegaye AT, Melaku T, Kefale B. Coping Strategies for Adverse Effects of Antiretroviral Therapy among Adult HIV Patients Attending University of Gondar Referral Hospital, Gondar, Northwest Ethiopia: A Cross-Sectional Study. AIDS Res Treat. 2018;2018(December). doi:10.1155/2018/1879198 